\title{
New developments in managing opioid addiction: impact of a subdermal buprenorphine implant
}

This article was published in the following Dove Press journal:

Drug Design, Development and Therapy

10 May 2017

Number of times this article has been viewed

\section{MariaLisa Itzoe \\ Michael Guarnieri}

Department of Neurological Surgery, Johns Hopkins School of Medicine, Baltimore, MD, USA

Video abstract

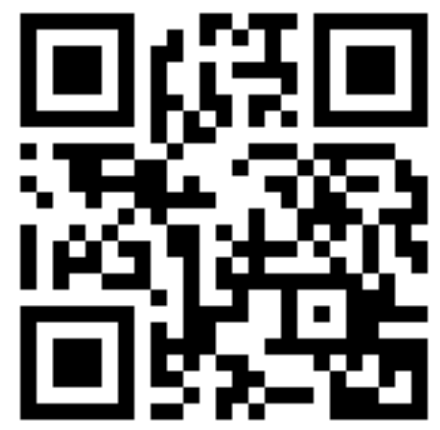

Point your SmartPhone at the code above. If you have a QR code reader the video abstract will appear. Or use: http://youtu.be/N $7 \mathrm{FqPek} 4 \mathrm{~m}$

Correspondence: Michael Guarnieri Department of Neurological Surgery, Johns Hopkins School of Medicine, I550 Orleans St, Rm 2M5I, Baltimore, MD, 21231 , USA

Tel +| 410614 |79|

Email mguarnieri@comcast.net
Abstract: Opioid addiction to prescription and illicit drugs is a serious and growing problem. In the US alone, $>2.4$ million people suffer from opioid use disorder. Government and pharmaceutical agencies have begun to address this crisis with recently released and revised task forces and medication-assisted therapies (MAT). For decades, oral or intravenous (IV) MATs have helped patients in their recovery by administration of opioid agonists (methadone, buprenorphine, oxycodone), antagonists (naltrexone, naloxone), and combinations of the two (buprenorphine/naloxone). While shown to be successful, particularly when combined with psychological counseling, oral and IV forms of treatment come with constraints and challenges. Patients can become addicted to the agonists themselves, and there is increased risk for diversion, abuse, or missed dosages. Consequently, long-acting implants have begun to be developed as a potentially preferable method of agonist delivery. To date, the newest implant approved by the US Food and Drug Administration (May 2016) is Probuphine ${ }^{\circledR}$, which delivers steady-state levels of buprenorphine over the course of 6 months. Numerous studies have demonstrated its efficacy and safety. Yet, implants come with their own risks such as surgical site irritation, possible movement, and protrusion of implant out of skin. This review introduces the opioid abuse epidemic, examines existing medications used for therapy, and highlights Probuphine as a new treatment option. Costs associated with MATs are also discussed.

Keywords: addiction, opioids, medication-assisted therapy, long-acting implant, buprenorphine, Probuphine ${ }^{\circledR}$

\section{Introduction to the opioid addiction crisis}

As of 2017, the importance of addressing opioid addiction and opioid use disorder (OUD) has been acknowledged as an issue of public health, with $>\$ 1$ billion being directed to this purpose in the US alone. ${ }^{1}$ This disorder is generally defined as having both the physical dependence on the drug and the psychological addiction to it, described by difficulties in controlling drug use, despite negative consequences, giving drug use top priority above other activities, and developing tolerance. ${ }^{2}$ There are many signs of opioid abuse, both physical and behavioral. Elation, somnolence, pupil constriction, intermittent confusion, slowed breathing, unstable mood, and constipation may occur. ${ }^{3}$ An abuser may be found "doctor shopping" (obtaining opioid prescriptions from different providers), having financial problems, or becoming secretive and isolated. ${ }^{3}$ Withdrawal symptoms are often unpleasant, such as headache, nausea, vomiting, diarrhea, sweating, fatigue, and insomnia. ${ }^{3}$

Addiction has been described as a progressive, chronic disease of "brain reward, motivation, memory [...] characterized by impulse control [...] cycles of relapse and remission". ${ }^{4}$ Across a 12-year period, from 2002 to 2014, the recorded number of deaths in the US from addiction to opioid analgesics doubled, whereas the death 
toll from heroin overdose quadrupled. ${ }^{5-7}$ More than 2.4 million Americans are suffering from OUD as defined by the dependence on an opioid medication, whether prescription or not. ${ }^{8}$ Worldwide statistics regarding opioid addiction are less clear, probably because many countries lack appropriate methods of gathering such information. However, as of 2015, Australian researchers used data from the World Health Organization and the United Nations Office on Drugs and Crime to estimate that $\sim 15$ million people, globally, use injection drugs such as heroin. ${ }^{9}$

There is no doubt that the financial burden of addiction has significantly grown, with the US Department of Health and Human Services calling the situation an "epidemic". ${ }^{10}$ This crisis has begun to be approached in a multifaceted way by educating prescribers to avoid overprescription of opioids, thus decreasing patients' access to drugs while also providing a variety of treatment options and increasing patients' access to them. The American Medical Association (AMA) has developed a "task force" devoted to decreasing abuse of opioid prescriptions and outlined five main goals as follows: 1) increase registration of physicians who are prescribing opioids, 2) increase physician education, 3) decrease stigma associated with pain, 4) decrease the substance use disorder stigma and expand treatment, and 5) broaden access to naloxone, an overdose reversal agent. ${ }^{11}$ The AMA task force has increased the awareness of this issue, prompted physicians prescribing opioids to register with prescription drug monitoring programs, and broadened education on alternative methods of managing patients' pain. ${ }^{12}$ In addition, the US Senate passed the Comprehensive Addiction and Recovery Act, signed into law on July 2016, with the aim of also addressing the OUD epidemic. ${ }^{13}$

\section{Therapies for opioid addiction}

The common opioids utilized for abuse include opium, heroin, morphine, oxycodone, hydrocodone, codeine, and fentanyl, the latter five of which are available as legal prescriptions. ${ }^{3}$ Medication-assisted treatment (MAT), provided by opioid treatment programs (OTPs), has become an accepted, though some say underused, approach toward targeting opioid addiction. ${ }^{10,14,15}$ It combines behavioral, cognitive, and pharmaceutical therapies while transferring the location of medication administration from the street into a clinic, thereby decreasing the risk of infection. ${ }^{2}$ Systems of MAT began in the early 20th century, though the modern concept of dispensing opioids in a controlled manner was first recommended by the New York Academy of Medicine in the 1950 s and the $1960 \mathrm{~s} .{ }^{10,17}$ MAT has also been shown to significantly decrease the chances of relapse in OUD; without it, relapse rates can exceed $80 \% .{ }^{17}$ Because we are focusing on the pharmacology of abuse deterrence, a review of these treatment models is beyond the scope of this report.

Table 1 provides a list of the available products used to treat opioid dependence. The three primary medications are methadone, buprenorphine, and naltrexone, with buprenorphine being the most commonly covered by insurance. ${ }^{10}$ Oral methadone (a full opioid receptor agonist), buprenorphine (a partial agonist), and naltrexone (a receptor antagonist) are used to minimize withdrawal symptoms experienced during recovery from opioid addiction. . $^{5,18}$ They do not usually cause euphoric sensations or highs associated with other opioids. ${ }^{13}$ Whereas agonists maintain physical tolerance and a form of opioid dependence, antagonists block the effects of opioids and require patients to undergo detoxification prior to treatment induction. ${ }^{14}$ Despite their differences, all three medications allow for psychological rehabilitation and

Table I Comparison of commonly available products to treat opioid dependence

\begin{tabular}{|c|c|c|c|c|}
\hline Drugs & Active ingredients & Administration & Average dosage/target range & Half-life \\
\hline Revia $^{\circledR}$, Depade ${ }^{\circledR}$ & Naltrexone & Oral (tablet) & $50 \mathrm{mg}, \mathrm{I} \times /$ day & 13 hours $^{45}$ \\
\hline Vivitrol $^{\circledR} \mathrm{XR}$ & Naltrexone & IM & $380 \mathrm{mg}, \mathrm{I} \times /$ month & $5-10$ days $^{59}$ \\
\hline $\begin{array}{l}\text { Methadose }{ }^{\circledR} \text {, Diskets }{ }^{\circledR}, \\
\text { Dolophine }^{\circledR}\end{array}$ & Methadone $\mathrm{HCl}$ & $\begin{array}{l}\text { Oral (dispersible } \\
\text { tablet in liquid), IM }\end{array}$ & $\begin{array}{l}\text { 2:I (parental-to-oral ratio), } \\
80-120 \mathrm{mg} \text { oral }^{60}\end{array}$ & $8-59$ hours $^{61}$ \\
\hline Xtampza ${ }^{\circledR}$ ER & Oxycodone $\mathrm{HCl}$ & Oral (capsule) & $9-36 \mathrm{mg}, 2 \times /$ day $^{62}$ & 5.6 hours $^{63}$ \\
\hline Narcan $^{\circledR}$ & Naloxone $\mathrm{HCl}$ & Nasal spray & 4 mg, I spray ${ }^{33}$ & $0.5-1.35$ hours $^{64}$ \\
\hline Suboxone ${ }^{\circledR}$ & Buprenorphine/naloxone & $\begin{array}{l}\text { Oral (SL) tablet, } \\
\text { buccal (film) }\end{array}$ & $4 / 1 \mathrm{mg}, 8 / 2 \mathrm{mg}, 12 / 3 \mathrm{mg}^{62}$ & $24-42$ hours/2-12 hours ${ }^{65}$ \\
\hline Bunavail $^{\circledR}$ & Buprenorphine/naloxone & Buccal (film) & $2.1 / 0.3 \mathrm{mg}, 4.2 / 0.7 \mathrm{mg}, 6.3 / \mathrm{l} \mathrm{mg}^{66}$ & 16.4-27.5 hours/1.9-2.4 hours ${ }^{67}$ \\
\hline Zubsolv $^{\circledR}$ & Buprenorphine/naloxone & Oral (SL) tablet & $\begin{array}{l}\text { Two } 5.7 \mathrm{mg} / \mathrm{I} .4 \mathrm{mg} \text { tablets } \\
\mathrm{I} \times / \text { day }(\mathrm{I} \mathrm{I} .4 \mathrm{mg} / 2.8 \mathrm{mg})^{68}\end{array}$ & $24-48$ hours/2-12 hours 65 \\
\hline Probuphine ${ }^{\circledR}$ & Buprenorphine $\mathrm{HCl}$ & Subdermal implant & $\begin{array}{l}\text { Four implants deliver equivalent } \\
\text { to daily doses }<8 \mathrm{mg} \text { suboxone }{ }^{55}\end{array}$ & $24-48$ hours $^{55}$ \\
\hline
\end{tabular}

Abbreviations: IM, intramuscular; IV, intravenous; SL, sublingual. 
may decrease emotional discomfort by stabilizing opioid receptors and facilitating cognition. ${ }^{18}$

A challenging aspect with both buprenorphine and methadone therapy is that patients can switch their addictions from the opioid to one of these agonists, consequently, becoming caught in a cycle of addiction. This is a major issue and has become a significant social problem. Indeed, buprenorphine abuse has become a noteworthy finding in countries such as Finland, Georgia, and Mauritius, where it is shown that many of intravenous (IV) drug users inject buprenorphine rather than heroin or other opioids because it is significantly less expensive and has long-lasting effects. ${ }^{19-22}$ Facilities such as the Coleman Institute treat both opioid addiction and opioid agonist addiction (to drugs such as Suboxone ${ }^{\circledR}$ and methadone) with the opioid antagonist naltrexone. ${ }^{23}$ This blocks opiate receptors, reduces cravings, and is nonaddictive. Comprehensive treatment plans, which include psychological counseling, behavioral modification, and social support programs, are crucial adjuncts for patients undergoing medication therapies to help prevent dangerous addictive cycles.

Although MAT holds promise for OUD therapy, there are certain requirements that physicians in the US must meet, in accordance with the Substance Abuse and Mental Health Services Administration (SAMHSA), prior to being able to prescribe medications outside of an OTP. SAMHSA's Division of Pharmacologic Therapies offers opioid-prescribing courses for providers, which involve training and resources to address management, legal, and regulatory issues; opioid pharmacology; and strategies for handling difficult patient situations. ${ }^{24}$ Such courses would be required for the prescription of naltrexone and methadone. In the case of buprenorphine, arguably more convenient than methadone as it can be prescribed outpatient, a special 8-hour certification course and license are necessary, as is either a US Drug Enforcement Agency Waiver or physician classification as an "addiction specialist". ${ }^{25}$ Moreover, a provider is only allowed to prescribe buprenorphine to 30 patients at one time; after 1 year, the provider can apply to begin treating up to 100 patients. ${ }^{26}$ The Department of Health and Human Services' Final Rule (published on July 8, 2016) allows providers to then request the approval to treat 275 patients as laid out by the Controlled Substance Act. ${ }^{27}$ Nevertheless, these limitations on the number of total MAT patients may be seen as barriers to accessibility of medication therapies for patients who may benefit.

Another important aspect to acknowledge about MAT is the cost, despite the evidence that it has significant economic benefits. In 2007, the National Drug Intelligence Center estimated that illicit drug use cost the US US\$193 billion due to fees associated with health care, criminal justice, and decreased work productivity. ${ }^{15}$ Studying a group of 933 heroin addicts, Powers and Anglin ${ }^{28}$ completed a retrospective analysis of crime, arrest, and drug dealing, and found that the rates of all three decreased during the episodes of methadone maintenance treatment (MMT). Ball and Ross ${ }^{29}$ had found similar results: examining days with criminal activity patients across six different MMT programs, there was an average decrease by $91 \%$ from before and during treatment, specifically for patients who stayed in treatment for $\geq 1$ years. Whereas 1 year of prison per person is $\sim \$ 22,000$, MAT is annually $\sim \$ 4,000$; thus, there is a potential savings of $\$ 18,000$ if more finances were relegated to treatment and recovery to avoid ultimate incarceration. ${ }^{15}$ Nevertheless, there is often inadequate coverage for MAT by both private and public insurers. ${ }^{15}$ According to a 2013 survey by the American Society of Addiction Medicine, state Medicaid agencies underutilize MAT, placing limitations on the coverage for medications such as methadone, buprenorphine, and naltrexone. ${ }^{30}$ Although the Affordable Care Act requires many insurers to pay for addiction treatment, there are often restraints placed on care (such as dosage limits and length of treatment), which make MAT difficult to obtain. ${ }^{15}$ Many private insurers refuse MMT coverage, forcing patients to pay out of pocket or forego medication.

\section{Pros and cons of medication treatment: issues of compliance}

For those who receive MAT, there remain other challenges to completing a treatment regimen. Historically, the oral route of administration has been the primary treatment method; however, this lends itself to problems of compliance or overdosing. "Abuse deterrent" capsules, such as the long-acting Xtampza $^{\circledR}$ ER (active ingredient oxycodone), have sought to ameliorate such problems. ${ }^{31} \mathrm{Xtampza}^{\circledR} \mathrm{ER}$ is one of the five such opioid formulations considered abuse deterrent because their formulations include excipients that prevent patients from the common methods of abusing opioids, including consumption of multiple "intact dosage units". ${ }^{31}$ While shown to be effective, Xtampza ${ }^{\circledR}$ ER must be taken at the same time each day with the same amount of food. ${ }^{32}$ Such restrictions can limit the long-term feasibility of treatment. Other excipients can include opioid antagonists, such as naloxone, which is a temporary short-acting reversal agent that has higher affinity for opioid receptors in the brain than for the opioid itself. ${ }^{33}$ It is now available as a nasal spray, $\operatorname{Narcan}^{\circledR}$, and is specifically beneficial for preventing death from respiratory distress. ${ }^{33}$ 
Naloxone has also been combined with buprenorphine in certain medications such as Bunavail ${ }^{\circledR}$, a film placed on the inner cheek, and Suboxone, available in tablet and film form. Bunavail was approved by the Food and Drug Administration (FDA) in 2014; its proprietary buccal adhesive claims to have double the bioavailability of other films, a feature resulting in improved absorption and plasma levels of buprenorphine, thus allowing therapeutic results at lower dosages. ${ }^{34}$ Whereas sublingual medications require placement under tongue until they dissolve, the buccal film has no such restraints, and the patient may talk, swallow, and complete daily activities uninhibited. ${ }^{34}$ This makes sublingual formulations theoretically more versatile than other oral drugs. Nevertheless, certain patient populations - for example, those with hepatic insufficiency are not appropriate candidates for buprenorphine/naloxone. ${ }^{35,36}$ Instead, medications with a single active ingredient of buprenorphine are an alternative course of detoxication. Subutex ${ }^{\circledR}$ was a sublingual tablet form of buprenorphine and previously an alternative to Suboxone. ${ }^{37}$ However, it was discontinued in 2011 for reasons other than safety and effectiveness. ${ }^{38}$ Nevertheless, generic buprenorphine tablets are still being manufactured and are an appropriate option for patients who cannot take buprenorphine/naloxone. ${ }^{39}$ Any medications containing buprenorphine will partially activate opiate receptors and thus prevent symptoms of withdrawal. Buprenorphine will also attach more strongly to the receptors than drugs such as heroin, so even if a patient attempts to abuse opiates while simultaneously taking buprenorphine tablets or Suboxone, the opiate would have no effect and the experienced "high" would be decreased. ${ }^{40}$ The additional ingredient of naloxone in buprenorphine based therapies helps to prevent the medication from being abused as there is no associated high that might be experienced with opioid agonists such as pure buprenorphine. ${ }^{40}$ As an opioid antagonist, naloxone, blocks receptors and consequently results in significant withdrawal symptoms.

\section{Treatment options Opioid agonists}

Methadone (trade names Methadose ${ }^{\circledR}$, Diskets ${ }^{\circledR}$, and Dolophine ${ }^{\circledR}$ ) and buprenorphine (proprietary name Probuphine $^{\circledR}$ ) are the two opioid receptor agonists that are currently topline medications. It is believed that these drugs stabilize opioid signaling and thus minimize the addictive effects of abused opioids. MMT has been used since the 1960 s as a long-acting (24-36 hours) substitute opioid treatment and pain management. ${ }^{5,16,41}$ It is usually dispensed in $100 \mathrm{~mL}$ of liquid, taken orally and suppresses withdrawal symptoms, opioid cravings, and "highs" associated with heroin (a short-acting opioid, lasting 3-6 hours). Methadone itself does not induce intoxication, and tolerance to it develops slowly, thus allowing patients to be on MMT for longer periods of time. ${ }^{41}$ Fei Bing et $\mathrm{al}^{42}$ found that MMT can significantly improve the quality of life: measured by reduction in heroin use, injecting practices, crime, and improvement in social functioning and physical symptoms.

Interest in buprenorphine as a detoxification agent for OUD comes from its pharmacological properties and remarkable history of safety. Pharmacologically, whereas methadone is a full agonist to the $\mu$-opioid receptor, buprenorphine is a partial opioid agonist that has higher affinity for opioid receptors than does heroin. ${ }^{19}$ Unlike methadone, buprenorphine exhibits a ceiling effect, meaning that higher doses do not necessarily produce more positive mood or respiratory depression. The drug was invented in the late 1960s by scientists working for the British drug company Reckitt \& Colman. John Lewis and Alan Cowan were assigned to create a new, "miracle" analgesic based on the structure of morphine and having as much analgesic potential but less abuse potential and more safety. ${ }^{43}$ Whereas several compounds showed promise in animal studies, buprenorphine stood out from the rest. Its ratio of the lethal dose $\left(\mathrm{LD}_{50}\right)$ to the effective concentration $\left(\mathrm{EC}_{50}\right)$ was at least threefold higher than morphine, which was considered a safe analgesic in animals and humans. ${ }^{43,44}$ Unlike morphine, buprenorphine had little capacity to induce respiratory depression. However, the miracle appeared to be short lived. The oral drug was a commercial failure as a human analgesic. Oral morphine was absorbed faster and produced pain relief in patients more quickly than did buprenorphine. Moreover, the natural product was less expensive compared to the new synthetic drug. Nonetheless, buprenorphine survived commercially as a veterinary analgesic for subcutaneous (SC) delivery and as an experimental drug for detoxification of heroin addicts. Use as a detoxification drug spread rapidly in the early 1980 s but came to a halt in the later part of the decade as numerous case reports started to describe deaths associated with IV overdoses. Over the next decade, follow-up toxicology studies demonstrated that in virtually every case, the victim had mixed buprenorphine with lethal combinations of other drugs including heroin, methadone, and benzodiazepines. ${ }^{44}$ Nonetheless, it would be almost 10 years for detoxification specialists to fully reintroduce the use of buprenorphine.

\section{Opioid antagonists}

Narcotic antagonists such as naloxone (trade name Narcan ${ }^{\circledR}$ ) and naltrexone (trade names Revia ${ }^{\circledR}$, Depade $^{\circledR}$, and Vivitrol ${ }^{\circledR}$ ) 
have shown the modest efficacy in the treatment of both opiate addiction and alcohol dependence. ${ }^{45,46}$ Reviews have focused on clinical findings and pharmacogenetics of naltrexone, advantages and limitations of sustained release systems, and pharmacological studies of naltrexone depot formulations for the treatment of alcohol and opioid dependency. To date, three naltrexone implant systems have been developed and tested in humans. In this report, we summarize clinical data on commercially available injectable and implantable naltrexone sustained release systems and discuss their safety and tolerability aspects. Emphasis is also laid on recent developments in nanodrug delivery such as naltrexoneloaded micelles and nanogels and related research avenues. Due to their ability to increase the therapeutic index and to improve the selectivity of drugs (targeted delivery), nanodrug delivery systems are considered promising sustainable drug carriers for naltrexone, in addressing opiate and alcohol dependence. ${ }^{47,48}$

A recent case report showed that a sustained release implant of naltrexone decreased opioid dependence and prevented relapse in $83 \%$ of addicts after 1 year. ${ }^{19}$ The implantable naltrexone injection of $3.3 \mathrm{~g}$ blockades opioid receptors for $\sim 145$ days. ${ }^{49}$ Extended release naltrexone is available in forms that last for several weeks and for several months. Researchers have examined naltrexone for buprenorphine addiction, because - as mentioned earlier - patients may become addicted to the opioid agonist itself that maintains physical opioid dependence.

\section{Long-acting therapy}

In summarizing the utility of drugs to treat OUD, methadone, naltrexone, naloxone, and buprenorphine remain the frontline choices. Oral delivery of these drugs has historically been the primary method of treating opioid addiction. Until 2016 , buprenorphine was only available as a pill or film form that was placed under the tongue or inside of the patient's cheek. ${ }^{2}$ Doses of the oral form are required to be taken daily, which presents the possible problems of forgetting or missing them. Long-acting implants are becoming a preferred route of administration to overcome the barriers such as patient nonadherence, forgetfulness, diversion, or deliberate overdosing. Extended release formulations reduce dosage frequency and have the potential to benefit patients, particularly in rural environments where access to medical facilities or clinics may be limited. Research with long-acting formulations has taken two forms. The first is to design oral drugs that last for 24 hours. Because these drugs, such as Xtampza ${ }^{\circledR}$ ER (oxycodone) mentioned earlier, use higher concentrations of the active ingredient, they commonly add abuse deterrent elements, which prevent diversion of the drug to a liquid form for IV injection. The second approach to longacting drugs has been to combine the active ingredient with a biocompatible delivery scaffold that can be implanted SC. Depending on the chemical composition of the scaffold, it will release the active ingredient in days, weeks, or months. ${ }^{5}$ Long-acting implants of naltrexone or buprenorphine can last up to 6 months. ${ }^{2,4,5}$ At the time of this writing, the newest example of such an implant is Probuphine, examined more closely in the following section. ${ }^{2}$

\section{The Probuphine implant}

Studies examining the long-acting implant form of buprenorphine have shown this delivery method to have efficacy. ${ }^{50}$ A 6-month randomized, placebo-controlled trial that collected data from 18 US sites gathered data from 163 opioid-dependent adults aged $18-65$ years. ${ }^{51}$ Following induction with sublingual buprenorphine/naloxone, 108 patients received four $80 \mathrm{mg}$ buprenorphine implants and 55 received four placebo implants; all patients also received individualized drug counseling. Percentage of negative urine samples for illicit opioids was examined across weeks 1-16. The implant group had significantly more negative samples $(P=0.04)$; a mean of $40.7 \%$ of samples was negative in the implant group compared to $28.3 \%$ in the placebo group. The implant group also reported fewer clinician-related and patient-related withdrawal symptoms $(P<0.001$ and $P=0.004$, respectively) and higher global ratings by physicians of improvement $(P<0.001) .{ }^{51}$ Only minor adverse reactions at the implant sites were reported for both groups (56.5\% patients in the implant group and $52.7 \%$ in the placebo group). This early work provided additional evidence for buprenorphine's safety and efficacy.

Probuphine is the newest buprenorphine implant to date. It was approved in 2016 by the FDA for use in patients aged 16-65 years. ${ }^{2}$ One reason for the implant's development was to help avoid accidental poisoning of small children from ingestion of tablet forms of medications. A retrospective analysis of data from 2002 to 2005 reported that 54 of 86 cases from the Researched Abuse, Diversion, and Addiction-Related Surveillance System experienced toxic clinical side effects post ingestion of buprenorphine. ${ }^{52}$ Children who ingested $>2 \mathrm{mg}$ were more likely to experience the effects (most commonly lethargy, vomiting, miosis, and respiratory depression); ingestion of $>4$ mg definitely resulted in some effect. ${ }^{52}$ Although none of the reported overdoses in this study were fatal, opioid poisoning has been found to be the leading cause of death by poisoning in children. ${ }^{52,53}$ Thus, long-acting implants have significant potential to decrease childhood fatalities. 
Using the ProNeura ${ }^{\mathrm{TM}}$ drug delivery platform, Probuphine lasts up to 6 months, during which it provides patients with regulated, constant dosages that stabilize their blood levels with buprenorphine. ${ }^{2,4}$ ProNeura - a nonbiodegradable implant made of ethylene-vinyl acetate - is administered via a "short subdermal insertion procedure" usually in the upper arm of the patient. ${ }^{4}$ The solid matrix consisting of four 1-inchlong rods is removed when the period of drug treatment is complete. ${ }^{54}$ The ProNeura platform provides "continuous, long-term steady-state blood levels of medication", which in the case of Probuphine is buprenorphine. ${ }^{54}$ One benefit to this method is that it is convenient and may decrease patient nonadherence as a person does not need to remember to take a daily oral dose. It also decreases the likelihood of purposeful overdosing that might occur when on an oral regimen. The implant is placed in an outpatient setting, which avoids the potentially stressful environment of a hospital stay. Whereas sublingual forms of buprenorphine can deliver varying doses, the Probuphine implant has been created to stabilize the drug levels in the blood. The implant also helps protect against purposeful drug abuse or overdosing that might occur when patients are on a daily oral regimen and take more than the allotted dosage.

Potentially adverse but common side effects of Probuphine include headache, depression, constipation, nausea, vomiting, back pain, mouth pain, and injection site irritation. ${ }^{2}$ More serious complications, though rare, may occur during the insertion or removal of the implant. These include nerve or blood vessel injury, migration (movement) of the implant, and protrusion or expulsion of implant out of the skin. ${ }^{55}$ Bleeding, pain, swelling, and infection at the site of insertion or removal may also occur, as can arm numbness or weakness. ${ }^{55}$ Because of these possible risks, Probuphine is not available at retail pharmacies and must be placed by a delegated prescriber who has been trained in the Probuphine Risk Evaluation and Mitigation Strategy program. ${ }^{56}$

Rosenthal et a ${ }^{50}$ enrolled 177 patients who were previously clinically stable on $\leq 8 \mathrm{mg}$ of sublingual buprenorphine/ naloxone for maintenance therapy for a 24-week doubleblind Phase III study of the Probuphine implant. ${ }^{57}$ About half of the subjects ( 87 patients) were randomly assigned to receive four $80 \mathrm{mg}$ buprenorphine implants with placebo sublingual Probuphine tablets, and the others received placebo implants with daily sublingual form of buprenorphine (90 patients) for a duration of 6 months. Study "responders" were defined as remaining abstinent from illicit opioids for $\geq 4$ out of 6 months as tested via urine sample and selfreport. ${ }^{54}$ There were more responders in the Probuphine arm than in the sublingual group $(96.4 \%$ vs $87.6 \%, P<0.001$ for non-inferiority), and a significantly greater number of patients remained abstinent from abused opioids, evidenced by negative urine tests, in the Probuphine group than in the sublingual group $(85.7 \%$ vs $71.9 \%, P=0.03))^{50,57}$ These findings provide evidence that the Probuphine implant has the potential to improve the quality of life of patients, avoid accidental overdose or purposeful medication diversion, and circumvent behaviors that might perpetuate the cycle of addiction.

Still, despite its strengths, it is important to acknowledge the limitations to the Phase III study. More adverse events, though classified as "mild" per clinical investigators, were experienced by the buprenorphine implant group (48.3\% nonimplant related and $23 \%$ implant related) compared to the sublingual buprenorphine group (52.8\% nonimplant related and $13.5 \%$ implant related). Currently, the FDA only approves 1 year of the medication, or two rounds of implants, and it is only approved for use among a limited patient population - those who have demonstrated clinical stability from previous oral regimens of the drug. ${ }^{5}$ This approval requires patients be relatively secure in their recovery before they can utilize Probuphine.

As noted earlier in this review, additional physician training is required to prescribe opioid agonists and antagonists; Probuphine is no exception. The certification process includes the basic information about the drug, how to select appropriate patient candidates for treatment, proper methods of insertion and removal of the implant, and hands on training using simulation models. ${ }^{4}$ The most common specialties receiving certification include occupational medicine, psychiatry, internal/family medicine, surgery, anesthesiology, and obstetrics/gynecology. ${ }^{4}$

\section{Conclusion: Probuphine implant's place in therapy}

The opioid epidemic is a major public health concern facing today's society. If trends continue, the number of those addicted might again double by 2024 . As shown in Table 1 , there are various medications for the treatment of OUD. Buprenorphine - a strong partial opioid receptor agonist with relative ease of accessibility, lower cost, and long-lasting effects - has unique and significant potential. For years, oral administration of buprenorphine either in pill or in sublingual forms has been used as a medication therapy. Implants offer an alternative, longer acting method of stabilizing blood levels of medication. Buprenorphine provides steady drug amounts for up to 6 months and diminishes the sensations of highs and lows often associated with abuse and withdrawal. ${ }^{2}$ This would overcome the challenge of patients missing doses 
and allow more consistency with MAT, which is correlated to lower risk of death. ${ }^{2}$ The opioid epidemic is thus being tackled on a variety of fronts, with Probuphine as an expectant pharmaceutical forerunner. Simultaneously, a comprehensive Opioid Action Plan set forth by the FDA is taking steps to reduce further opioid abuse. The plan includes expanding use of advisory committees for medication approval, developing better warnings and safety information, enforcing requirements to generate postmarket data on long-term use of opioid medications, updating Risk Evaluation and Mitigation Strategy programs, and increasing education surrounding opioid medication use and prescription. ${ }^{58}$

Future research should include investigations into longterm effects of Probuphine, consequences of expanding the demographic to patients not previously clinically stable on medication, and the development of alternative options for treatment. Moreover, studies should compare the Probuphine implant to other medications such Bunavail, Suboxone, Zubsolv (all buprenorphine/naloxone combination drugs), or naltrexone. It may also be beneficial to examine if there are consequences from the surgical procedure of implant placement and removal. Although these are possible directions for researchers, it is critical to recall that MAT alone is not as beneficial as combined MAT with psychological counseling. Ideally, such therapy would be added to any pharmaceutical regimen to provide additional support and resources for patients on their path to recovery.

\section{Disclosure}

The authors report no conflicts of interest in this work.

\section{References}

1. Office of the Press Secretary of the White House. President Obama proposes $\$ 1.1$ billion in new funding to address the prescription opioid abuse and heroin use epidemic. J Pain Palliative Care Pharmacother. 2016; 30(2):134-137.

2. US Food and Drug Administration [webpage on the Internet]. FDA News Release: FDA approves first buprenorphine implant for treatment of opioid dependence [updated May 26, 2016]. Available from: http://www. fda.gov/NewsEvents/Newsroom/PressAnnouncements/ucm503719.htm. Accessed March 26, 2017.

3. Drug Abuse.com [webpage on the Internet]. Treatment. Opiate Abuse [updated 2017]. Available from: http://drugabuse.com/library/opiateabuse/. Accessed March 23, 2017.

4. Titan Pharmaceuticals Inc [webpage on the Internet]. Product Pipeline: Probuphine [updated 2017]. Available from: http://www.titanpharm. com/pipeline/probuphine. Accessed March 26, 2017.

5. Compton W, Volkow N. Improving outcomes for persons with opioid use disorders buprenorphine implants to improve adherence and access to care. JAMA. 2016;316(3):277-278.

6. Substance Abuse and Mental Health Services Administration, Center for Behavioral Health Statistics and Quality [webpage on the Internet]. 2014 National Survey on Drug Use and Health: detailed tables. Tables 1.1-1.9. Available from: http://www.samhsa.gov/data/sites/ default/files/NSDUH-DetTabs2014/NSDUH-DetTabs2014.htm\#tab762a. Accessed March 26, 2017.
7. National Center for Health Statistics. Number and age-adjusted rates of drug-poisoning deaths involving opioid analgesics and heroin: United States, 1999-2014. Available from: http://www.cdc.gov/nchs/ data/health_policy/AADR_drug_poisoning_involving_OA_Heroin_ US_2000-2014.pdf. Accessed March 26, 2017.

8. Williams AR, Bisaga A. From AIDS to opioids - how to combat an epidemic. N Engl J Med. 2016;375:813-815.

9. Join Together Staff. Partnership for Drug Free Kids [webpage on the Internet]. Researchers release first report on worldwide addiction statistics [updated June 6, 2015]. Available from: http://drugfree.org/learn/ drug-and-alcohol-news/researchers-release-first-report-worldwideaddiction-statistics/. Accessed March 21, 2017.

10. Volkow N, Frieden T, Hyde P, Cha S. Medication assisted therapiestackling the opioid overdose epidemic. N Engl J Med. 2014;370(22): 2063-2066.

11. American Medical Association [webpage on the Internet]. Task Force to Reduce Opioid Abuse. Available from: https://www.amaassn.org/delivering-care/task-force-reduce-opioid-abuse. Accessed March 26, 2017.

12. Parks $T$ [webpage on the Internet]. AMA Wire: using neurosurgical solutions to manage chronic pain [updated August 23, 2016]. Available from: https://wire.ama-assn.org/delivering-care/using-neurosurgicalsolutions-manage-chronic-back-pain. Accessed March 26, 2017.

13. Nosyk B, Anglin M, Brisette S, et al. A call for evidence-based medical treatment of opioid dependence in the United States and Canada. Health Aff. 2013;32(8):1462-1469.

14. Lee JD, Nunes EV, Novo P, et al. NIDA Clinical Trials Network CTN-0051, extended release naltrexone vs buprenorphine for opioid treatment (X:BOT): study rationale and design. Contemp Clin Trials. 2016;50:253-264.

15. Legal Action Center. Confronting an Epidemic: The Case for Eliminating Barriers to Medication Assisted Treatment of Heroin and Opioid Addiction. 2015. Available from: https://lac.org/wpcontent/uploads/2014/07/LAC-The-Case-for-Eliminating-Barriersto-Medication-Assisted-Treatment.pdf. Accessed April 24, 2017.

16. Substance Abuse and Mental Health Services Administration [webpage on the Internet]. History of medication-assisted treatment for opioid addiction. Treatment Improvement Protocol (TIP) Series, No. 43. Rockville, MD: Johnson, Bassin, and Shaw; 2005. Available from: http:// www.ncbi.nlm.nih.gov/books/NBK64157/. Accessed April 6, 2017.

17. Medication-Assisted Treatment Improves Outcomes for Patients With Opioid Use Disorder [webpage on the Internet]. The Pew Charitable Trusts: 2016. Available from http://www.pewtrusts.org/en/researchand-analysis/fact-sheets/2016/11/medication-assisted-treatmentimproves-outcomes-for-patients-with-opioid-use-disorder. Accessed Aprile 24, 2017.

18. Volkow ND, Koob GF, McLellan AT. Neurobiological advances from the brain disease model of addiction. $N$ Engl J Med. 2016;374(4): $363-371$.

19. Jhugrool A, Ellayah D, Norman A, Hulse G. Naltrexone implant treatment for buprenorphine dependence - Mauritian case series. J Psychopharmacol. 2014;28(8):800-803.

20. INCB. Report of the International Narcotics Control Board for 2012. Report no. E/INCB/2012/1; 2013. Available from: https://www.incb. org/documents/Publications/AnnualReports/AR2012/AR_2012_E.pdf. Accessed March 26, 2017.

21. Otiashvili D, Zabransky T, Kirtadze I, Piralishvili G, Chavchanidze M, Miovsky M. Why do the Georgian needle exchange programmes inject buprenorphine? Eur Addict Res. 2010;16:1-8.

22. Simojoki K, Lillsunde P, Lintzeris N, Alho H. Bioavailability of buprenorphine from crushed and whole buprenorphine (subutex) tablets. Eur Addict Res. 2010;16(2):85-90.

23. The Coleman Institute [homepage on the Internet] [updated 2017]. Available from: http://thecolemaninstitute.com/. Accessed March 23, 2017.

24. SAMHSA [webpage on the Internet]. Opioid Prescribing Courses for Health Care Providers. [updated February 9, 2017]. Available from: https://www.samhsa.gov/medication-assisted-treatment/trainingresources/opioid-courses. Accessed March 23, 2017. 
25. SAMSHA [webpage on the Internet]. Buprenorphine Waiver Management. Rockville, MD: Substance Abuse of Mental Health Administration (SAMSHA) [updated February 9, 2017]. Available from: https:// www.samhsa.gov/medication-assisted-treatment/buprenorphinewaiver-management. Accessed March 23, 2017.

26. Stein B, Sorbero M, Dick A, Pacula L, Burns R, Gordon A. Physician capacity to treat opioid use disorder with buprenorphine-assisted treatment. JAMA. 2016;316(11):1211-1212.

27. SAMSHA/HHS [webpage on the Internet]. Medication Assisted Treatment for Opioid Use Disorder: Final Rule; 2016. Available from: https://www.federalregister.gov/documents/2016/07/08/2016-16120/ medication-assisted-treatment-for-opioid-use-disorders. Accessed March 26, 2017.

28. Powers A, Anglin M. Cumulative versus stabilizing effects of methadone maintenance. Eval Rev. 1993;17(3):243-270.

29. Ball J, Ross A. The Effectiveness of Methadone Maintenance Treatment. New York, NY: Springer-Verlag; 1991.

30. The American Society for Addiction Medicine [webpage on the Internet]. Advancing Access to Addiction Medications: Implications for Opioid Addiction Treatment; 2013. Available from: http://www. asam.org/docs/default-source/advocacy/aaam_implications-for-opioidaddiction-treatment_final. Accessed March 28, 2017.

31. The Medical Letter Inc [webpage on the Internet]. A New Abuse Deterrent Opioid-Xtampza ER from The Medical Letter on Drugs and Therapeutics; 2016. Available from: http://secure.medicalletter.org/ w1497a. Accessed March 24, 2017.

32. Blank $\mathrm{C}$ [webpage on the Internet]. FDA Panel backs extended-release painkiller, but not an immediate release one. Drug Topics Voice of the Pharmacist. Modern Medicine Network [updated September 15, 2015]. Available from: http://drugtopics.modernmedicine.com/drug-topics/ news/fda-panel-backs-extended-release-painkiller-not-immediaterelease-one. Accessed March 17, 2017.

33. ADAPT Pharma, Inc [webpage on the Internet]. NARCAN ${ }^{\circledR}$ Nasal Spray 4mg [updated 2016]. Available from: https://www.narcan.com/?\&gcli d=CMDZ3qDg29ICFVOHswodajIA6w. Accessed March 26, 2017.

34. Cassels $C$ [webpage on the Internet]. FDA approves Bunavail for opioid addiction. Medscape. 2014. Available from: http://www.medscape.com/ viewarticle/826473. Accessed March 27, 2017.

35. Indivior Inc [webpage on the Internet]. How to Take Suboxone Film [updated 2016]. Available from: http://www.suboxone.com/medicaltreatment/how-to-take-suboxone. Accessed March 22, 2017.

36. Highlights of prescribing information: Bunavail [prescribing information]; 2016. Available from: https://www.accessdata.fda.gov/drugsatfda_docs/ label/2016/205637s011lbl.pdf. Accessed March 27, 2016.

37. RxList [webpage on the Internet]. Subutex [updated January 9, 2017]. Available from: http://www.rxlist.com/subutex-drug/side-effectsinteractions.htm. Accessed March 21, 2017.

38. Federal Register [webpage on the Internet]. Determination That SUBUTEX (Buprenorphine Hydrochloride) Sublingual Tablets, Equivalent 2 Milligrams Base and Equivalent 8 Milligrams Base, Were Not Withdrawn From Sale for Reasons of Safety or Effectiveness [updated February 13, 2015]. Available from: https://www. federalregister.gov/documents/2015/02/13/2015-03001/determinationthat-subutex-buprenorphine-hydrochloride-sublingual-tablets-equivalent-2-milligrams\#footnote-1-p8088. Accessed March 30, 2017.

39. Actavis UK Ltd [webpage on the Internet]. Buprenorphine $0.4 \mathrm{mg}, 2 \mathrm{mg}$ and $8 \mathrm{mg}$ Sublingual Tablets [updated February 26, 2016]. Available from: https://www.medicines.org.uk/emc/medicine/26589. Accessed March 30, 2017.

40. CRH Health [webpage on the Internet]. Suboxone vs. Subutex: What's the Difference? (and which one is right for you?). Available from: http://www.crchealth.com/addiction/heroin-addiction-treatment/heroindetox/buprenorphine-suboxone-vs/. Accessed March 23, 2017.

41. Knowledge Exchange Archive [webpage on the Internet]. Overview of methadone maintenance treatment. Available from: https://www. porticonetwork.ca/web/knowledgex-archive/amh-specialists/overviewmmt. Accessed January 9, 2016.
42. Fei Bing JT, Yee A, Habil MH, Danaee M. Effectiveness of methadone maintenance therapy and improvement in quality of life following a decade of implementation. $J$ Subst Abuse Treat. 2016;69:50-56.

43. Cowan A. Buprenorphine: new pharmacological aspects. Int J Clin Pract Suppl. 2003;113:3-8.

44. Campbell N, Lovell A. The history of the development of buprenorphine as an addiction therapeutic. Ann N Y Acad Sci. 2012;1248:124-139.

45. SAMHSA/CSAT. Oral naltrexone. In: US Department of Health and Human Services, Treatment Improvement Protocol (TIP) Series, No 49. Rockville, MD: Center for Substance Abuse Treatment; 2009:27-35.

46. Hubbell C, Czirr S, Hunter G, Beaman C, LeCann N, Reid L. Consumption of ethanol solution is potentiated by morphine and attenuated by naloxone persistently across repeated daily administrations. Alcohol. 1986;3(1):39-54.

47. Goonoo N, Bhaw-Luximon A, Ujoodha R, Jhugroo A, Hulse GK, Jhurry D. Naltrexone: a review of existing sustained drug delivery systems and emerging nano-based systems. J Control Release. 2014; 183:154-166.

48. Daubresse M, Saloner B, Pollack HA, Caleb Alexander G [webpage on the Internet]. Non-buprenorphine opioid utilization among patients using buprenorphine. Addiction. 2017. Available from: http:// onlinelibrary.wiley.com/wol1/doi/10.1111/add.13762/full. Accessed March 24, 2017.

49. Ngo H, Arnold-Reed D, Hansson R, Tait R, Hulse G. Blood naltrexone levels over time following Naltrexone implant. Prog Neuropsychopharmacol Biol Psychiatry. 2008;32(1):23-28.

50. Rosenthal R, Lofwall M, Kim S, Chen M, Vocci F. Effect of buprenorphine implants on illicit opioid use among abstinent adults with opioid dependence treated with sublingual buprenorphine: a randomized clinical trial. JAMA. 2016;316(3):282-290.

51. Ling W, Casadonte P, Bigelow G, et al. Buprenorphine implants for treatment of opioid dependence: a randomized controlled trial. JAMA. 2010;304(14):1576-1583

52. Hayes B, Klein-Schwartz W, Doyan S. Toxicity of buprenorphine overdoses in children. Pediatrics. 2008;121(4): e782-e786.

53. Nickson $C$ [webpage on the Internet]. Suboxone poisoning. Life in the Fast Lane [updated March 29, 2017]. Available from: https://lifeinthefastlane.com/toxicology-conundrum-006/. Accessed March 30, 2017.

54. Titan Pharmaceuticals [webpage on the Internet]. Titan Pharmaceuticals reports positive results from phase 3 study of probuphine for opioid addiction [updated June 8, 2015]. Available from: http:// www.titanpharm.com/news/press-releases/detail/38/titan-pharmaceuticals-reports-positive-results-from-phase-3. Accessed March 26, 2017.

55. RxList [webpage on the Internet]. Probuphine [updated June 2, 2016]. Available from: http://www.rxlist.com/probuphine-drug/clinicalpharmacology.htm. Accessed March 21, 2017.

56. Braeburn Pharmaceuticals [homepage on the Internet]. Probuphine Risk Evaluation and Mitigation Strategy (REMS) Program. Available from: http://probuphinerems.com/. Accessed March 29, 2017.

57. Braeburn Pharmaceuticals [webpage on the Internet]. Braeburn Pharmaceuticals Reports Positive Results From Phase 3 Study of Probuphine $^{\circledR}$ for Opioid Addiction [June 8, 2015]. Available from: https://braeburnpharmaceuticals.com/braeburn-pharmaceuticalsreports-positive-results-from-phase-3-study-of-probuphine-for-opioidaddiction/. Accessed March 28, 2017

58. US Food and Drug Administration [webpage on the Internet]. FDA Opioids Action Plan [updated September 9, 2016]. Available from: https://www.fda.gov/NewsEvents/Newsroom/FactSheets/ucm 484714 . htm. Accessed March 26, 2017.

59. RxList [webpage on the Internet]. Vivitrol [updated 2017]. Available from: http://www.rxlist.com/vivitrol-drug/clinical-pharmacology.htm. Accessed March 21, 2017.

60. US Food and Drug Administration [webpage on the Internet]. Information for Healthcare Professionals Methadone Hydrochloride [updated August 23, 2013] Available from: https://www.fda.gov/Drugs/DrugSafety/ucm142841.htm. Accessed March 21, 2017. 
61. Drugs.com [webpage on the Internet]. Methadone Dosage [updated 2017]. Available from: https:/www.drugs.com/dosage/methadone. html. Accessed March 21, 2017.

62. Drugs.com [webpage on the Internet]. Xtampza ER Dosage [updated 2017]. Available from: https://www.drugs.com/dosage/xtampza-er. html. Accessed March 21, 2017.

63. Xtampza ER [webpage on the Internet]. Epocrates Inc [updated 2017] Available from: https://online.epocrates.com/drugs/753907/ Xtampza-ER/Pharmacology. Accessed March 21, 2017.

64. RxList [webpage on the Internet]. Narcan [updated January 13, 2017]. Available from: http://www.rxlist.com/narcan-drug/clinical-pharmacology.htm. Accessed March 21, 2017.

65. RxList [webpage on the Internet]. Suboxone [updated 2017]. Available from: http://www.rxlist.com/suboxone-drug/clinical-pharmacology. htm. Accessed March 21, 2017.
66. BioDelivery Sciences International, Inc. Bunavail Dosing and Administration Guide [updated February 2015]. Available from: https://bunavail. com/hcp/pdf/BUNAVAIL_Dosing_Guide.pdf?pdf=BUNAVAILDosing-Guide. Accessed March 21, 2017.

67. RxList [webpage on the Internet]. Bunavail [updated 2017]. Available from: http://www.rxlist.com/bunavail-drug.htm. Accessed March 21, 2017.

68. Zubsolv Dosage \& Administration [webpage on the Internet] [updated 2016]. Available from: https://www.zubsolv.com/zubsolv/dosingadministration/. Accessed April 14, 2017.

\section{Publish your work in this journal}

Drug Design, Development and Therapy is an international, peerreviewed open-access journal that spans the spectrum of drug design and development through to clinical applications. Clinical outcomes, patient safety, and programs for the development and effective, safe, and sustained use of medicines are the features of the journal, which has also been accepted for indexing on PubMed Central. The manuscript management system is completely online and includes a very quick and fair peer-review system, which is all easy to use. Visit http://www.dovepress.com/testimonials.php to read real quotes from published authors.

Submit your manuscript here: http://www.dovepress.com/drug-design-development-and-therapy-journal 